\title{
Metode Bayesian Networks untuk Menyelesaikan Occlusion pada Object Tracking
}

\author{
Ikhwan B. Zarkasi, Rose Maulidiyatul H, Dina Nurul Fitria* \\ Program Studi Teknik Informatika, Fakultas Sains dan Teknologi, \\ Universitas Al Azhar Indonesia, Jl. Sisingamangaraja, Jakarta 12110 \\ *Penulis untuk Korespondensi: dina.fitria@uai.ac.id
}

\begin{abstract}
Abstrak - Banyak cara untuk dapat mendeteksi keamanan sebuah wilayah tertentu. Salah satu cara pengamanan yang bisa digunakan adalah dengan menggunakan pemantauan berbasis video pengawasan (video surveillance). Sebenarnya, video pengawasan sudah banyak digunakan di Indonesia. Tetapi, umumnya video pengawasan ini hanya mampu merekam gambar, tanpa ada kemampuan pintar yakni, object tracking, object recognition dan object analyzing. Sehingga, hasil yang diharapkan kurang maksimal dan belum bisa membantu tugas pengawasan secara keseluruhan. Paper ini bertujuan untuk membuat algoritma dari object tracking yang ada pada video pengawasan sebagai rujukan pengembangan video pengawasan dengan kemampuan object recognition dan object analyzing. Masalah utama yang sering muncul dalam pembuatan object tracking adalah ketika terjadi occlusion (tumpang tindih) antara dua object dalam sebuah frame. Pada saat occlusion, object yang sama pada frame yang berbeda kemungkinan dapat dikenali sebagai object yang berbeda. Sehingga, proses object tracking akan menjadi terganggu. Bayesian Networks memungkinkan untuk membandingkan data yang didapat dari masing-masing object yang ada (likelihood) dengan data awal yang telah dimiliki (prior), dengan menghitung Maximum A-Posteriori Probability(MAP) yang dimiliki, sehingga object yang sama pada frame yang berbeda tetap akan dikenali sebagai object yang sama
\end{abstract}

Abstract - There are many ways/technique to detect the security/safety of fixed area. One of security technique that can be used is by using monitoring based on Video surveillance. In fact, this monitoring video has already been used in Indonesia. But, video surveillance, commonly, just can record images without any smart abilities, such as object tracking, object recognition and object analyzing. So, the expected result is not optimal and still not be able to help monitoring role totally. This research is aimed to make the algorithm of object trackingin video surveillance, in order to be reference for development of video surveillance with ability of object recognition and object analyzing. The main problem that frequently comes up on the making of object tracking is occlusion between two objects in a single frame. When occlusion is happened, same object in different frame probably can be recognized as two different objects. So, the process of object tracking can be disturbed. Bayesian Network is enable to compare data that got from every object (likelihood) with prior data that has already been provided by counting its Maximum A-Posteriori Probability (MAP), so same object in different frame are still be able to be recognized as same object.

Keywords - Bayesian Network, occlusion, object tracking, algoritma, Maximum A-Posteriori Probability (MAP).

\section{PENDAHULUAN}

$\mathrm{P}$ emantauan berbasis video pengawasan banyak digunakan di Indonesia untuk pengawasan keamanan ruang publik. Tetapi, umumnya video pengawasanini hanya mampu merekam gambar tanpa memiliki kemampuan pintar. Selain itu, video pengawasanini membutuhkan operator untuk mengawasi video, sehingga akan meningkatkan resiko terjadinya human error yang dikarenakan kelelahan, kejenuhan dan berbagai faktor yang lain. 
Tugas pengawasan ini akan terbantu jika video pengawasan memiliki kemampuan untuk dapat mendeteksi dan mengenali benda (object) yang berada dalam ruang terbatas, baik itu posisi ataupun kegiatan yang sedang dilakukan oleh object tersebut. Dengan kemampuan ini, operator tidak perlu ada didepan video pengawasan sepanjang waktu.Untuk dapat membuat video pengawasan dengan kemampuan tersebut, maka perlu dipecahkan permasalahan yang mungkin muncul pada saat pendeteksian dan pengenalan benda seperti object tracking.

Masalah yang sering ditemukan dalam pembuatan algoritma object tracking adalah adanya occlusion antara object yang berbeda. Terdapat beberapa metode yang dapat digunakan untuk menyelesaikan permasalahan occlusion, seperti HOG, Ecpectation Maximization Algorithm, Hybrid Strategy, Online Adaptive Neural Classifier atau Bayesian Network $^{[1]}$. Semua metode tersebut menggunakan kesamaan karakteristik object dalam menyelesaikan permasalahan occlusion, tanpa memperdulikan pengetahuan awal yang ada, berdasarkan percobaan yang telah dilakukan sebelumnya. Tetapi pada Bayesian Network, pengetahuan awal tersebut digunakan, selain penggunaan kesamaan karakteristik untuk menyelesaikan permasalahan occlusion. Dengan menggunakan pengetahuan awal ini maka dimungkinkan hasil yang didapatkan untuk pemilihan object menjadi lebih robust. Karena itu, paper ini menggunakan metode Bayesian Networkuntuk penyelesaian occlusion.

Terdapat beberapa paper ilmiah yang mengulas tentang penggunaan Bayesian Network untuk penyelesaian masalah occlusion ${ }^{[2,3,4,5]}$. Paper ilmiah tersebut digunakan sebagai rujukan dalam pembuatan paper ini. Dalam paper ini, pengenalan terhadap object yang sama hanya dilakukan terhadap object sebelum dan sesudah occlusion. Untuk object yang merupakan hasil occlusion, akan dikenali sebagai object baru. Tugas akhir ini hanya membahas penyelesaian occlusion menggunakan Bayesian Network tanpa melakukan perbandingan lebih lanjut dengan metode yang lain.

\section{TINJAUAN PUSTAKA}

Perancangan algoritma object tracking pada paper ini terbagi menjadi 3 modul besar yakni, object segmentation, regionlinking dan object tracking.

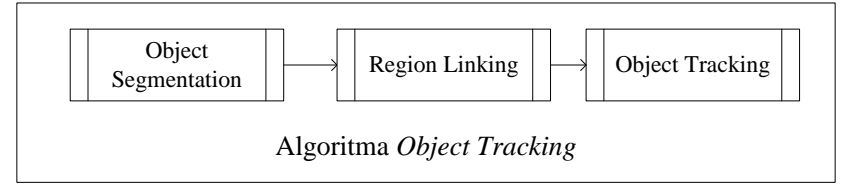

Gambar 1. Algoritma global object tracking

Modul object segmentation digunakan untuk memisahkan atau mengisolasi object yang bergerak dari background yang ada. Sehingga akan didapatkan masing-masing object dalam 1 frame.

Modul region linking digunakan untuk menghubungkan masing-masing object yang sama dalam frame berbeda, sehingga akan terbentuk hubungan antar object yang sama yang digunakan untuk proses selanjutnya.

Modul object tracking digunakan untuk memberikan label kepada object yang sama dalam frame berbeda. Walaupun object tadi merupakan object hasil dari occlusion.

Masing-masing modul tersebut akan diulas dalam bab pembahasan.

\section{METODOLOGI PENELITIAN}

Modul object segmentation ini menggunakan algoritma background substraction(BS) untuk memisahkan object yang diobservasi dari background yang ada. Karena hasil dari background substraction biasanya masih banyak mengandung noise atau derau, maka dilakukan morphological process(MP) sebagai proses lanjutan. Tujuan dari morphological processini adalah sebagai filter untuk membersihkan frame dari noise.

Morphological process yang digunakan tergantung dari seberapa besar serta bentuk dari noise yang ada. Cara yang umum digunakan bisa menggunakan dilation, erotion, closing, opening atau median filter. Contoh hasil dari object segmentation ini adalah: 

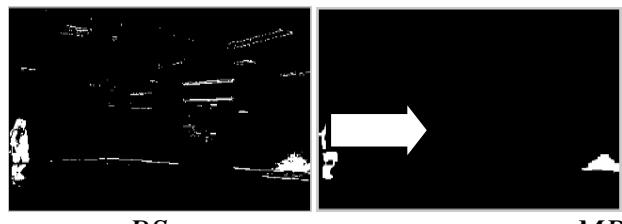

$B S$

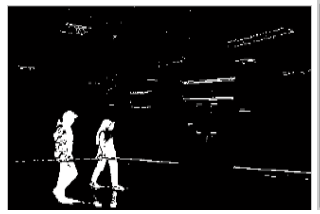

$B S$

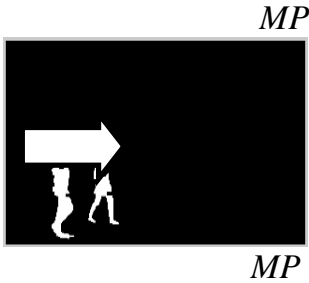

Gambar 2. Hasil Segmentasi Frame ke-49 dan 125 pada percobaan video pertama

\section{HASIL DAN PEMBAHASAN}

Region linking ini digunakan untuk menghubungkan object yang sama dalam frame berbeda. Object yang telah didapatkan dari modul object segmentation akan dibandingkan karakteristiknya dengan object pada frame sebelumnya. Apabila terdapat perbedaaan yang kecil (masih dalam batas threshold yang ditentukan) dalam karakteristiknya, maka kedua object tersebut akan dibuat suatu hubungan.

Karakteristik yang digunakan disini adalah warna, area dan centroid. Untuk menghitung besar perbedaan karakteristiknya, digunakan persamaan Euclidean distance :

$$
d_{i j}=\left\|x_{i}-y_{j}\right\|=\sqrt{\left(x_{1 i}-y_{1 j}\right)^{2}+\cdots+\left(x_{p i}-y_{p j}\right)^{2}}
$$

dengan $\boldsymbol{x}_{(i j)}$ adalah object pada current frame (frame yang diamati), dan ${ }^{y_{(i j)}}$ adalah object yang ada pada frame sebelumnya atau reference frame.

Hasil dari modul ini adalah trajectory atau hubungan antar object yang sama dalam frame berbeda yang tersimpan dalam suatu matriks. Disini, juga dilakukan pengendalian terhadap noise yang tidak terhapus dalam modul object segmentation.Suatu object akan dianggap sebagai noise jika trajectory yang dihasilkan tidak terlalu panjang.

Modul object tracking ini berfungsi untuk memberikan label terhadap masing-masing object yang terdeteksi. Untuk object yang sama akan diberikan label yang sama meskipun berada dalam frame yang berbeda. Masukan dari modul ini adalah matriks hasil dari region linking. Matriks ini menggambarkan hubungan antara object yang sama dalam frame yang berbeda. Apabila terjadi occlusion, maka matriks yang dihasilkan akan menjadi rusak sehingga dibutuhkan modul object tracking untuk memberikan label yang tepat.Modul ini terbagi menjadi 4 tahap :

\subsection{Make Graphical Model}

Pada tahap ini akan dibuat hubungan antar object yang berbeda. Object yang berbeda didapatkan dari trajectory yang dihasilkan modul region linking. Untuk memudahkan, satu trajectory menggambarkan sebuah object, dan sebuah object diwakili oleh sebuah node. Semua node ini akan dihubungkan, sehingga akan terbentuk hubungan parent dan child antar node.

Pada paper ini diberikan batasan maksimal jumlah parent dan node sebesar $2^{[4]}$.

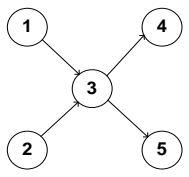

Gambar 3. Contoh graphical model percobaan video pertama

\subsection{Make Admissible Label}

Setelah didapatkan graphical model dari masingmasing node, maka akan dicari kemungkinan label yang dimiliki oleh sebuah node, kemungkinan label ini merupakan gabungan dari label parent dari node yang diamati dengan label baru yang diberikan kepada node yang diamati.

$$
L_{i}=\left[\bigcup_{j \in E_{i}} L_{j_{j}}\right] \cup L_{\text {new }}
$$

Dimana : $L_{i}:$ kemungkinan label node yang sedang diamati

$L_{j}$ : gabungan kemungkinan label semua node parent dari node yang sedang diamati

$L_{\text {new }}$ : label baru yang dimiliki oleh node yang sedang diamati

\subsection{Choose Label}

Dari kemungkinan label yang didapatkan, maka akan dilakukan pemilihan, label mana yang paling cocok untuk node yang diamati. Pemilihan ini dilakukan dengan menghitung Bayesian Networks yang dimiliki oleh masing-masing node yang diamati. Persamaan Bayesian Networks yang digunakan : 


$$
\boldsymbol{P}\left(\boldsymbol{A}_{i} \mid \boldsymbol{B}\right)=\frac{\boldsymbol{P}\left(\boldsymbol{B} \mid \boldsymbol{A}_{i}\right) \boldsymbol{P}(\boldsymbol{A})}{\boldsymbol{\Sigma} \boldsymbol{P}\left(\boldsymbol{B} \mid \boldsymbol{A}_{i}\right) \boldsymbol{P}(\boldsymbol{A})} \longrightarrow f(\theta \mid X)=\frac{f(X \mid \theta) f(\theta)}{f(X)}
$$

karena besar pembagi (evidence) selalu sama untuk masing-masing node dalam satu percobaan, maka persamaan diatas bisa ditulis :

$$
f(\theta \mid X) \propto f(X \mid \theta) f(\theta)
$$

Persamaan tersebut merupakan perkalian dari likelihood dan prior yang dimiliki oleh masingmasing node. Prior, merupakan data subjektif awal yang dimiliki oleh masing-masing node berdasarkan percobaan yang telah dilakukan. Dalam paper ini, nilai prior ditentukan berdasarkan jumlah dari parent yang dimiliki oleh node yang sedang diamati, yakni :

$$
\text { prior }= \begin{cases}P_{\text {new }} & \text { if Parent }<2 \\ \frac{1-P_{\text {new }}}{n} & \text { if Parent }=2\end{cases}
$$

Sedangkan, likelihood merupakan data percobaan yang dimiliki oleh masing-masing node.Likelihood ini bersifat random. Perhitungan likelihood dalam paper ini berdasarkan karakteristik yang dimiliki oleh suatu node. karakteristik yang digunakan ada 6 yakni :
- luas area
- kecepatan rata-rata
- arah
- rata-rata warna merah
- rata-rata warna hijau
- rata-rata warna biru.

Karakteristik yang dimiliki tersebut akan dibandingkan dengan masing-masing kemungkinan label yang dimiliki oleh node yang diamati. Perhitungan besar likelihood ini dilakukan dengan menggunakan persamaan distribusi binomial :

$$
x=\sum_{k=1}^{K}\left(\left(\begin{array}{l}
n \\
k
\end{array}\right) P^{k}(1-P)^{(n-k)}\right)
$$

dimana : $K=$ jumlah kemiripan karakteristik yang dimiliki oleh node yang diamati dibandingkan dengan kemungkinan label yang diberikan

$n=$ jumlah karakteristik yang dibandingkan (untuk tugas akhir ini bernilai 6)
$P \quad=$ probabilitas untuk kemiripan 1 buah karakteristik (probabilitas kejadian sukses)
$1-P=$ probabilitas kejadian gagal

Setelah didapatkan nilai prior dan likelihood untuk masing-masing node, mengadopsi teori MAP (Maximum A-posteriori Probability), maka pemilihan label dilakukan dengan mengambil nilai maksimal dari perkalian yang dihasilkan.

$$
\text { posterior }=\max (\text { likelihood } * \text { prior })
$$

\subsection{Update Matrix}

Matriks yang dihasilkan pada modul region linking, selanjutnya akan di-update berdasarkan label yang telah didapatkan. Sehingga, akan diperoleh label yang sama untuk object yang sama.

\subsection{Uji Coba}

Eksperimen dilakukan dengan menggunakan 6 buah video dengan keadaan dan jumlah object yang berbeda. Jumlah object bervariasi mulai dari 2 hingga 4 object. Video yang digunakan diperoleh dari hasil perekaman menggunakan kamera Canon Powershot A580 dengan resolusi 320x240. Pengambilan gambar ini dilakukan di 2 tempat yakni lantai 6 serta lantai 3 Universitas Al-Azhar Indonesia, sekitar pukul $13.00-15.00$ tanpa menggunakan lampu penerangan (hanya menggunakan sinar matahari). Tiap video yang diambil memiliki durasi berkisar antara $10-20$ detik dan memiliki kecepatan 25fps

Percobaan Pertama:

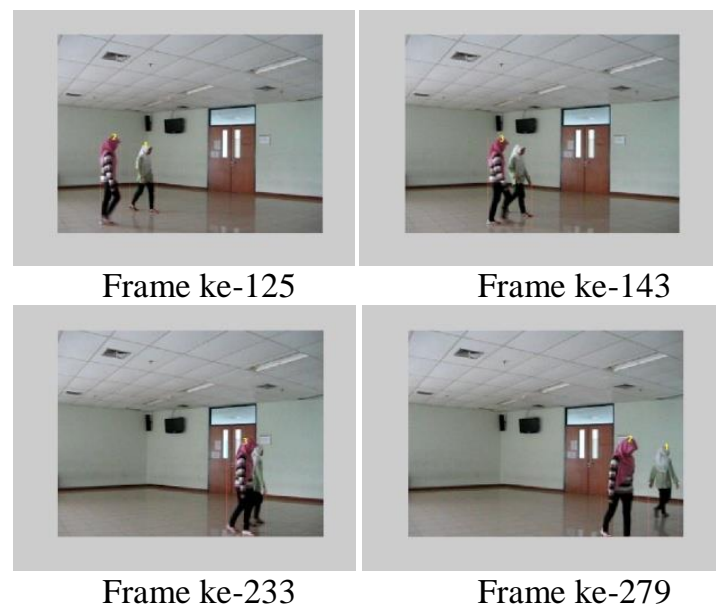

Gambar 4. Hasil Object Tracking pada percobaan video pertama 
Percobaan ketiga:

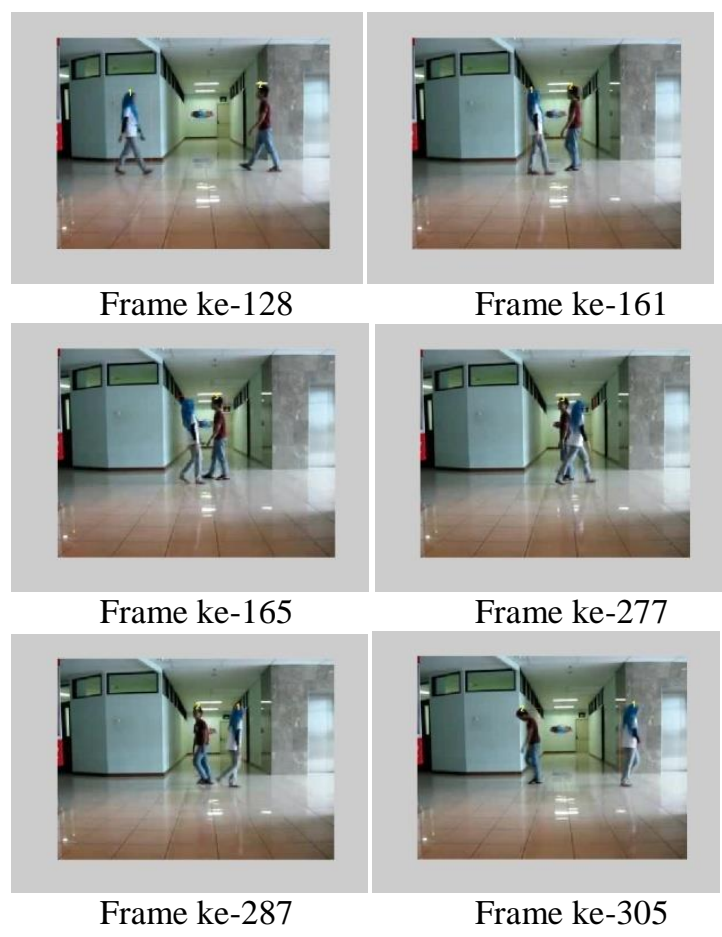

Gambar 5. Hasil Object Tracking pada percobaan video ketiga

Percobaan keenam:

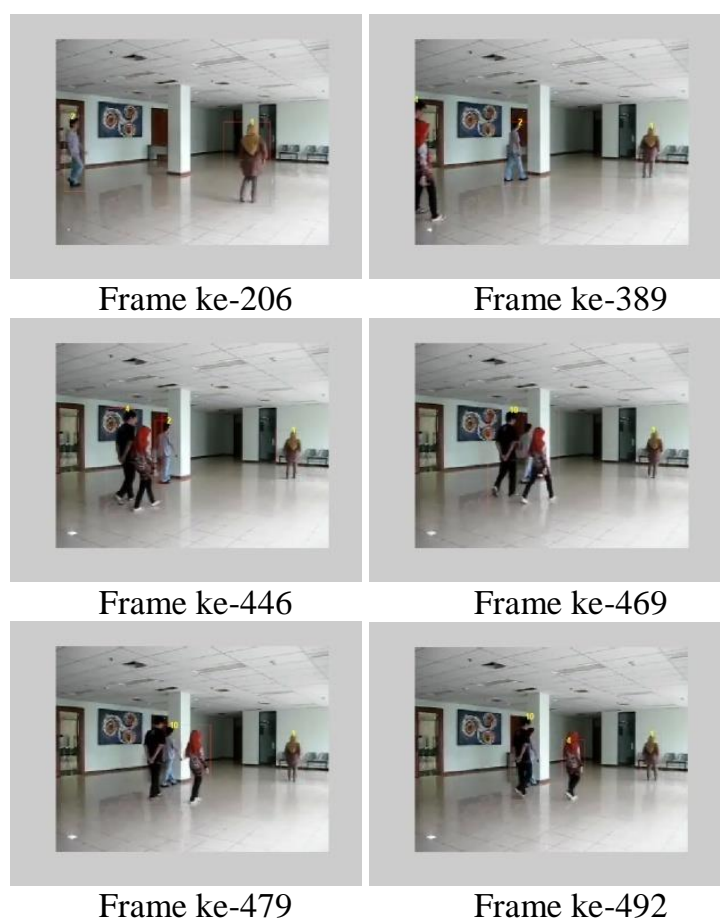

Gambar 6. Hasil Object Tracking pada percobaan video keenam
Hampir semua orang dapat dikenali dan diberikan label yang sesuai, kecuali untuk video yang keenam. Di video keenam terdapat 2 object yang tidak dapat dikenali sempurna, hal ini disebabkan karena, object yang ada sebelum occlusion dan object yang dihasilkan sesudah occlusion merupakan object yang sama sekali berbeda (gabungan dari beberapa object). Metode Bayesian dapat digunakan dengan sempurna untuk semua video (kecuali video keenam). Percobaan yang dilakukan disini menggunakan object yang memiliki warnabaju yang berbeda, meskipun ada beberapa object yang memiliki warna baju agak mirip (video keempat, kelima dan keenam).

Waktu rata-rata pemrosesan untuk setiap frame dalam video diatas berbeda satu sama lain, tergantung dari object yang terdeteksi dalam masing-masing video dan lama video yang diproses. Semakin banyak object yang terdeteksi atau semakin panjang video inputan, maka waktu yang dibutuhkan semakin lama. Untuk tugas akhir ini waktu rata-rata yang dibutuhkan untuk memproses sebuah frame (dari semua rata-rata waktu yang dibutuhkan untuk semua video) adalah 0.49 detik. Performansi ini dilakukan dengan menggunakan komputer dengan spesifikasi Processor Intel(R) Pentium(R) Dual CPU T2390 @ $1.86 \mathrm{GHz}$ dan RAM sebesar 1014MB.Untuk lebih jelasnya dapat dilihat dari tabel dibawah ini:

Tabel 1. Waktu yang dibutuhkan untuk memroses video

\begin{tabular}{lccc}
\hline Video & $\begin{array}{c}\text { Panjang } \\
\text { (frame) }\end{array}$ & $\begin{array}{c}\text { Waktu } \\
\text { total (dtk) }\end{array}$ & $\begin{array}{c}\text { Waktu rata- } \\
\text { rata/frame } \\
\text { (dtk) }\end{array}$ \\
\hline pertama & 350 & 133.05 & 0.38 \\
kedua & 392 & 142.89 & 0.36 \\
ketiga & 357 & 159.23 & 0.45 \\
keempat & 313 & 146.48 & 0.47 \\
kelima & 420 & 268.961 & 0.64 \\
keenam & 497 & 304.68 & 0.61 \\
Total & 2329 & 1155.29 & 0.49 \\
\hline
\end{tabular}

\section{KESIMPULAN}

1. Untuk mendapatkan hasil object tracking yang robust, maka proses segmentasi harus dilakukan dengan benar. Jika segmentasi yang dihasilkan tidak sempurna, maka banyak noise yang akan ikut terdeteksi sehingga mengganggu proses object tracking.

2. Metode Bayesian Networks, dapat digunakan untuk menyelesaikan permasalahan occlusion 
yang ada pada object tracking, dengan pen getahuan awal (prior) yang dimiliki.

3. Algoritma object tracking ini sangat dipengaruhi oleh banyak object yang terdeteksi serta panjang video masukan. Semakin banyak object yang terdeteksi atau semakin panjang video masukan, maka semakin lama waktu yang dibutuhkan untuk melakukan pemrosesan.

4. Performansi algoritma object tracking ini cukup bagus. Hal ini terlihat dari hasil pelabelan terhadap object yang terdeteksi dan waktu rata-rata yang dibutuhkan untuk memproses sebuah frame, yakni sebesar 0.4960 detik. Performansi ini dilakukan dengan menggunakan computer dengan spesifikasi Processor Intel(R) Pentium(R) Dual CPU T2390 @ $1.86 \mathrm{GHz}$ dan RAM sebesar 1014MB.

\section{DAFTAR ACUAN / PUSTAKA}

[1] P. Bilinski, F. Bremond, M. Becha Kaaniche, "Multiple Object Tracking with Occlusion Using HOG Descriptors and Multi Resolution Images," IEEE, 2004.

[2] A. Abrantes, J. Marques, and J. Lemos, "Long Term Tracking Using Bayesian Network," IEEE ICIP., III:609-612, September 2002.

[3] M. Narayana, D. Haverkamp, "A Bayesian algorithm for tracking multiple moving objects in outdoor surveillance video," IEEE CVPR.,pp.1-8, June 2007.

[4] P. Jorge, J. Marques, and A. Abrantes, "Estimation of the Bayesian Network Architecture for Object Tracking in Video Sequence," ICPR'04vol2.,pp.732-735, August 2004.

[5] B. Han, Y. Zhu, D. Comaniciu, and L. Davis, "Kernel Based bayesian Filtering for Object Tracking," IEEE CVPR'05-vol1, June 2005.

[6] Gonzalez, Rafael C., Woods, Richard E., Digital Image Processing Second Edition. Prentice Hall, New Jersey, 2002.

[7] Walpole, Ronald E., Myers, Raymond H., Myers, Sharon L., Ye, Keying., Probability \& Statistic for Engineers \& Scientist Seventh Edition. Prentice Hall, New Jersey, 2002 